\title{
Detection of Simple, Complex, and Clonal Chromosome Translocations Induced by Internal Radioiodine Exposure: A Cytogenetic Follow-Up Case Study after 25 Years
}

\author{
Gordon K. Livingston ${ }^{\text {a Terri L. Ryan }}{ }^{\text {a Tammy L. Smith }}{ }^{\text {a }}$ Maria B. Escalona ${ }^{a}$ \\ Alvis E. Foster ${ }^{b}$ Adayabalam S. Balajee ${ }^{a}$ \\ ${ }^{a}$ Radiation Emergency Assistance Center/Training Site, Cytogenetic Biodosimetry Laboratory, Oak Ridge Institute \\ for Science and Education, Oak Ridge Associated Universities, Oak Ridge, TN, USA; ${ }^{b}$ Indiana University Health, Ball \\ Memorial Hospital, Muncie, IN, USA
}

\section{Keywords}

Chromosome inversions · Genomic instability · Internal radiation exposure $\cdot$ Radioiodine therapy $\cdot$ Retrospective biodosimetry. Simple and complex chromosome translocations

\begin{abstract}
Here, we report the findings of a 25 -year cytogenetic followup study on a male patient who received 2 rounds of radioiodine treatment within a span of 26 months $(1.78 \mathrm{GBq}$ in 1992 and $14.5 \mathrm{GBq}$ in 1994). The patient was 34 years old with a body mass index of 25 at the time of the first radioiodine treatment. Multicolor FISH and multicolor banding (mBAND) techniques performed on the patient detected inter- and intrachromosomal exchanges. Although the frequency of chromosome translocations remained essentially the same as reported in our earlier study $(0.09 /$ cell), the percentage of reciprocal (balanced) translocations increased from 54.38 to $80.30 \%$ in the current study. In addition to simple chromosome translocations, complex exchanges $(0.29 \%)$ involving more than 2 chromosomes were detected for the first time in this patient. Strikingly, a clonal translocation involving chromosomes 14 and $15, t(14 p ; 15 q)$, was found in 7
\end{abstract}

of the 677 cells examined (1.03\%). The presence of complex and clonal translocations indicates the onset of chromosomal instability induced by internal radioiodine exposure. mBAND analysis using probes specific for chromosomes 1, 2, 4,5 , and 10 revealed 5 inversions in a total of 717 cells $(0.69 \%)$, and this inversion frequency is several-fold higher than the baseline frequency reported in healthy individuals using the classical G-banding technique. Collectively, our study suggests that stable chromosome aberrations such as translocations and inversions can be useful not only for retrospective biodosimetry but also for long-term monitoring of chromosomal instability caused by past radioiodine exposure.

(c) 2019 S. Karger AG, Basel

The use of radiopharmaceutical agents has gained prominence in the fields of nuclear medicine and oncology since the 1940s for diagnosis and treatment of various human diseases including cancer. Radioiodine $\left({ }^{131} \mathrm{I}\right)$ is one such extensively used agent in the treatment of hyperthyroidism and as an effective ablative therapy for thyroid cancer. In fact, radioiodine constitutes as much as $90 \%$ of all the currently used therapies in nuclear medicine. Increasing use of radioiodine in nuclear medicine

\section{KARGER}

(c) 2019 S. Karger AG, Basel

E-Mail karger@karger.com

www.karger.com/cgr
Adayabalam S. Balajee, Ph.D.

Radiation Emergency Assistance Center/Training Site

Cytogenetic Biodosimetry Laboratory, Oak Ridge Institute for Science and Education

Oak Ridge Associated Universities, 1299, Bethel Valley Road

Oak Ridge, TN 37830 (USA), E-Mail adayabalam.balajee@orau.org 
warrants a thorough evaluation of potential biological effects caused either prospectively or retrospectively in radioiodine therapy (RIT) patients. Despite the fact that radioisotope ${ }^{131} \mathrm{I}$ has a short half-life of 8 days and an even shorter biological half-life of 24 hours, the impact of radioiodine on chromosomal damage has been well-documented in the literature [Nofal and Beierwaltes, 1964; Cantolino et al., 1966; Sanders, 1967; Llloyd et al., 1976; Ardito et al., 1987; Lehmann et al., 1996; Wuttke et al., 1996; Lassmann et al., 2005; Popova et al., 2005; Iarmarcovai et al., 2008; Serna et al., 2008; Frigo et al., 2009; Joseph et al., 2009; da Silva et al., 2016; Livingston et al., 2016; Khvostunov et al., 2017]. Upon administration, ${ }^{131}$ I decays by emitting a combination of $\gamma$-rays and $\beta$-particles throughout the body leading to induction of DNA damage and chromosomal aberrations. Since information on biological effects of internal radiation exposure is highly restricted, thyroid cancer patients undergoing ablative RIT provide a unique opportunity for a systematic evaluation of acute and chronic biological effects of internal radiation delivered under carefully controlled conditions.

Induction of DNA single- and double-strand breaks by radioiodine has been reported earlier [Hengstler et al., 1997; Lassmann et al., 2010; Hershman et al., 2011]. Consistent with the in vivo formation of DNA double-strand breaks [Lassmann et al., 2010], our earlier studies [Livingston et al., 1993, 2016, 2018] documented elevated levels of micronuclei (MN) and translocations in the peripheral blood lymphocytes of a radiotherapy patient. The patient received an ablative RIT (1.78 GBq) for his papillary thyroid carcinoma in 1992 when he was 34 years of age with a BMI of 25. Prior to this treatment, the patient did not have any kind of ionizing radiation exposure(s). Twenty-six months after the first RIT, the patient received the second treatment in 1994 involving a much higher radioiodine activity (14.5 GBq) for a suspicious lesion in the lung. The cytokinesis-blocked micronucleus assay performed on the blood sample of this patient 11 days after the first therapy in 1992 and at monthly intervals over a period of 8 months showed that the MN frequency was at least 4-6-fold higher than the baseline frequency detected prior to RIT [Livingston et al., 1993]. Based on the elevated $\mathrm{MN}$ frequency, an absorbed dose of 11 cGy was predicted for the peripheral blood after RIT. A subsequent follow-up study on this patient using fluorescence in situ hybridization (FISH) in 2012 [Livingston et al., 2018] revealed elevated frequencies of both unstable and stable chromosomal aberrations indicating the persistence of radioiodine-induced chromosomal aberrations. Livingston et al. [2016] detected 41 translocations per 1,000 genome equivalent (GE) cells in the patient by FISH using a cocktail of DNA probes specific for chromosomes 2, 4, and 12. The multicolor FISH (mFISH) technique performed on this patient's sample in 2015 detected 95 translocations in 1,000 cells indicating a significant elevation in chromosome translocation frequency compared to the FISH analysis performed in 2012 [Livingston et al., 2018]. The detection of an elevated translocation frequency in the patient's blood sample analyzed in 2015 (21 years after the second radioiodine exposure in 1994) suggests that the onset of delayed genomic instability may be responsible for the potentiation of chromosomal aberrations. Besides translocations, other aberrations indicative of chromosomal instability were also observed: 3 chromatid breaks in chromosomes 2,5 , and $\mathrm{X}, 1$ chromosome break in chromosome 4, and 12 acentric fragments ( 3 of chromosome 1, 2 of chromosome 4, 2 of chromosome 5, 2 of chromosome 20, and 1 each of chromosomes 3, 9, and 19) [Livingston et al., 2018]. Numerical alterations were also observed involving 8 hypodiploid ( $<46$ chromosomes) and 12 hyperdiploid ( $>46$ chromosomes) cells in a total of 600 cells analyzed by mFISH. Observation of both numerical and structural chromosome alterations indicates RIT-induced chromosomal instability. The main objectives of the current 25-year follow-up study were to investigate the retrospective effects of RIT on stable and unstable chromosomal aberrations and to verify the progression of delayed chromosomal instability in the patient. Besides the evaluation of RIT-induced chromosomal aberrations in vivo, we wished to verify whether or not the past radioiodine exposure potentiates the yield of $\mathrm{X}$-ray-induced chromosomal aberrations in vitro by compromising the DNA repair response in this patient. Our results indicate the persistence and progression of RIT-induced chromosomal instability retrospectively and that long lasting stable chromosome translocations can be useful for retrospective biodosimetry after internal radioiodine exposure.

\section{Materials and Methods}

\section{Patient History}

The history of the male patient was already described in an earlier report [Livingston et al., 2018]. He was 34 years old when a total thyroidectomy procedure was performed on him in November of 1991 after the diagnosis of papillary thyroid cancer. In mid-January of 1992, the patient received the first ablative RIT $(1.78 \mathrm{GBq})$ for the elimination of any residual tumor cells. He received a second round of radioiodine treatment $(14.5 \mathrm{GBq})$ in mid-March of 1994 for a suspicious lesion in the lung. Prior to thyroid cancer diagnosis, the patient did not have any occupational or medical exposure to ionizing radiation. He had 1 neck and upper chest CT scan prior to 
Table 1. Baseline frequency of dicentric chromosomes in normal healthy donors and in the radioiodine therapy patient

\begin{tabular}{lllllll}
\hline Sample & Age & Gender & Cells analyzed & Dicentrics & Dicentrics/cell & Estimated dose, Gy (95\% CI) \\
\hline Donor 1 & 42 & Male & 9,331 & 5 & 0.0005 & 0 \\
Donor 2 & 32 & Male & 6,684 & 1 & 0.0001 & 0 \\
Donor 3 & 40 & Female & 7,885 & 4 & 0.0005 & 0 \\
Donor 4 & 61 & Male & 3,425 & 3 & 0.0009 & $0(0-0.03)$ \\
Donor 5 & 47 & Female & 2,116 & 7 & 0.003 & $0.05(0.0003-0.12)$ \\
Patient $^{\mathrm{a}}$ & 61 & Male & 500 & 3 & 0.006 & $0.11(0-0.296)$ \\
\hline
\end{tabular}

a Scored by FISH using centromere- and telomere-specific peptide nucleic acid probes.

Table 2. Chromosome translocations detected by mFISH in normal healthy donors and in the radioiodine therapy patient

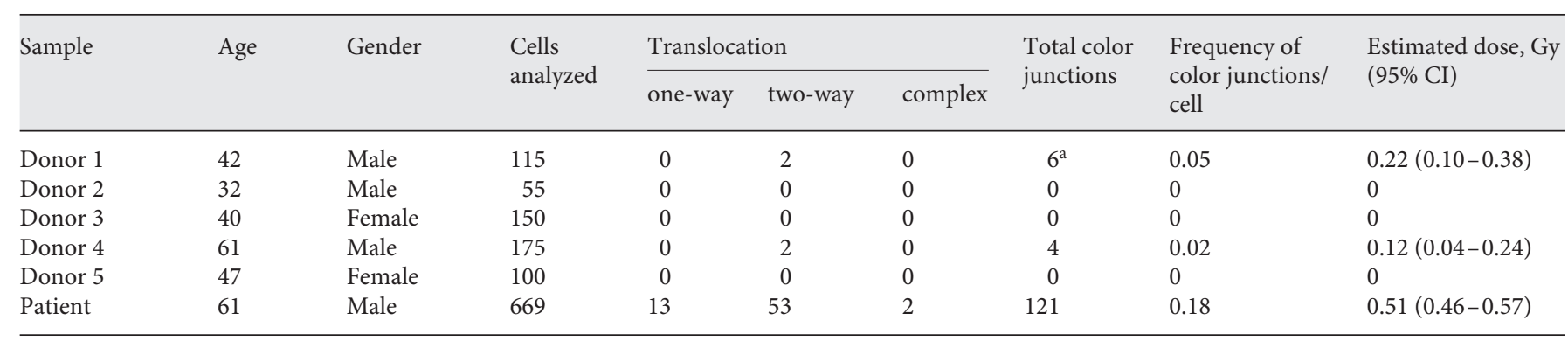

${ }^{a}$ Contained 1 dicentric chromosome with an acentric fragment.

surgery in November 1991 on a GE 9800 CT scanner with 30 mGy being the maximum estimated dose. It is known that the exposure dose from a CT scan varies greatly within the body, with most tissues receiving far less than the maximum estimated dose of $30 \mathrm{mGy}$. In addition to this, a few chest X-rays were taken, and the estimated cumulative dose was around $40 \mathrm{mGy}$ indicating that the diagnostic radiation exposure was insignificant relative to RIT. For the last several years before and after RIT, the patient has maintained a body weight of $205 \mathrm{lbs}$ with a BMI of 25. Ever since the first radioiodine treatment, we have been performing the cytogenetic follow-up study on this patient for almost 25 years. The latest blood collection from this patient was performed in the first week of April 2019 for an in-depth cytogenetic analysis to monitor the persistence and progression of chromosomal aberrations induced by RIT. The patient was healthy and free of cancer during the 25 years of follow-up.

\section{In vitro Lymphocyte Culture and Metaphase Chromosome}

Preparation

Blood samples obtained from healthy donors and the patient were used for the present study. The gender and age of the donors are listed in Tables 1,2, and 5. None of the donors is addicted to either cigarette smoking or alcohol and drug abuse. Blood samples were drawn after written consent of the donors in strict compliance with the Institutional Review Board protocol. Aliquots of blood samples $(500 \mu \mathrm{L})$ were either mock-irradiated or irradiated with different doses of X-rays ( $0 \mathrm{~Gy}, 0.5 \mathrm{~Gy}, 1 \mathrm{~Gy}, 2 \mathrm{~Gy}$, and $4 \mathrm{~Gy}$ ) using the facility at the University of Tennessee, Knoxville, TN (RS 2000; RAD Source, $0.3-\mathrm{mm}$ copper filter that allows $160-\mathrm{kV}$ operation at
$25 \mathrm{~mA}$; dose rate $2 \mathrm{~Gy} / \mathrm{min}$ ). Blood samples were cultured in complete growth medium (RPMI 1640 supplemented with 10\% fetal bovine serum, $2 \%$ phytohaemagglutinin, and the antibiotics penicillin and streptomycin). Bromodeoxyuridine was added to the cultures at a final concentration of $10 \mu \mathrm{M}$ to identify the first division metaphases. Cultures were harvested after $48 \mathrm{~h}$ including a treatment with colcemid $(0.1 \mu \mathrm{g} / \mathrm{mL})$ for the last $4 \mathrm{~h}$ to obtain metaphase chromosomes. For chromosome preparation, cells were first treated with a hypotonic solution $(0.56 \% \mathrm{KCl})$ for $16-18 \mathrm{~min}$ at $37^{\circ} \mathrm{C}$, followed by fixation in 3 changes of ice-cold acetic acid:methanol (1:3) mixture. Slides were prepared using $25-30 \mu \mathrm{L}$ of fixed cell suspension, and the preparations were treated with RNAse A for 30 min at $37^{\circ} \mathrm{C}$. Then, the slides were processed for FISH.

\section{FISH, $m$ FISH, and Multicolor Banding}

Metaphase chromosomes prepared from control and X-ray irradiated samples were subjected to FISH using human centromere- and telomere-specific peptide nucleic acid (PNA) probes for detecting unstable chromosome aberrations (dicentric and ring chromosomes). The FISH procedure was performed essentially as described before [Livingston et al., 2018; Ryan et al., 2019]. Telomere- and centromere-specific PNA probes (Cy3- and fluorescein-labeled, respectively) were procured from Bio PNA, USA. Fluorescence-tagged DNA probes for mFISH and chromosome-specific multicolor banding (mBAND) were obtained from MetaSystems, Boston, MA, USA. mFISH was performed essentially following the manufacturer's protocol (MetaSystems) for detecting genome wide spontaneous and X-ray-induced chromo- 
some translocations involving one-way, two-way, and complex exchanges as described before [Livingston et al., 2018; Ryan et al., 2019]. Briefly, slides were treated for 1-2 min in an acidic solution of pepsin $(0.001 \%)$ at $37^{\circ} \mathrm{C}$ followed by post-fixation for $10 \mathrm{~min}$ in $1 \times \mathrm{PBS}$ containing $1 \%$ formaldehyde and $50 \mathrm{mM} \mathrm{MgCl}_{2}$. After denaturation through a sequential treatment of $2 \times \mathrm{SSC}$ at $70^{\circ} \mathrm{C}$ for $20 \mathrm{~min}$ and $0.07 \mathrm{~N} \mathrm{NaOH}$ for $1 \mathrm{~min}$ at ambient temperature, the slides were dehydrated through a graded series of ethanol and airdried. The $\mathrm{mFISH}$ probe was separately denatured by incubation at $75^{\circ} \mathrm{C}$ for $5 \mathrm{~min}$ followed by incubation for $30 \mathrm{~min}$ at $37^{\circ} \mathrm{C}$ to enable annealing of highly repetitive DNA sequences. The slides were hybridized ( $8 \mu \mathrm{L}$ of probe/slide) for $72 \mathrm{~h}$ by placing them in a humidified chamber at $37^{\circ} \mathrm{C}$. Post-hybridization processing was performed by washing the slides for $5 \mathrm{~min}$ in a pre-warmed solution of $1 \times \mathrm{SSC}(\mathrm{pH} 7.0-7.5)$ at $75^{\circ} \mathrm{C}$ followed by 3 washes of $5 \mathrm{~min}$ each in $4 \times$ SSC/Tween 20 . After a final wash in $1 \times$ PBS, the slides were dehydrated through a graded ethanol series, air-dried, and stained with DAPI (Vector Laboratories, Burlingame, CA, USA). Images were captured using the metaphase finder program of Metafer under a $63 \times$ objective lens using an epifluorescence microscope (Carl Zeiss). Normal and aberrant chromosomes were identified by the ISIS software (MetaSystems) that generated a pseudo-color pattern for each pair of homologous chromosomes [Livingston et al., 2018; Ryan et al., 2019]. Color junctions were used to identify one-way (non-reciprocal), two-way (reciprocal), and complex chromosome exchanges (involving more than 2 chromosomes). Color junctions resulting from dicentric chromosome formation with accompanying acentric fragments were also included in the analysis.

To determine the frequency of chromosome inversions in the radioiodine patient, $\mathrm{mBAND}$ probes specific for chromosomes 1 , $2,4,5$, and 10 were utilized. The mBAND technique was essentially similar to $\mathrm{mFISH}$ as described above and the inversion events were scored by analyzing the sequential order of labeled chromosome fragments along the $\mathrm{p}$ - and $\mathrm{q}$-arms of specific chromosomes. Both intra-arm (paracentric inversions) and inter-arm (pericentric inversions) exchanges were analyzed.

\section{Statistical Analysis}

Data obtained on the incidence of unstable (dicentrics and rings) and stable (translocations and inversions) chromosome aberrations were presented as the mean \pm SEM. The Student paired $t$-test was performed to analyze the difference in spontaneous and ex vivo X-ray-induced chromosome aberration yields between normal healthy individuals and the radioiodine patient. A $p$ value $<0.05$ was considered to be significant.

\section{Results}

Persistence and Progression of RIT-Induced

Chromosomal Instability 25 Years after Radioiodine

\section{Treatment}

Our 21-year follow-up study involving FISH and $\mathrm{mFISH}$ revealed elevated frequencies of both unstable (dicentrics) and stable (translocations) chromosome aberrations in a radioiodine patient [Livingston et al., 2018]. The main purpose of this follow-up study was to verify whether or not RIT-induced chromosomal aberrations persist and progress retrospectively in this patient. Results on the frequencies of aberrations ( $\mathrm{MN}$, dicentrics, rings, and translocations) detected during the longitudinal study in the radioiodine patient are shown in Figure 1. The significant increase noted in $\mathrm{MN}$ frequency soon after the first and second radioiodine treatments clearly indicated that the elevation of MN was mainly due to internal radiation exposure [Livingston et al., 1993, 2016, 2018].

The baseline frequency of dicentrics in the general population is $0.001 /$ cell ( 1 dicentric chromosome in 1,000 metaphase cells) [IAEA, 2011], and it is not drastically affected by either gender or age. In our previous study, we detected 5 dicentric chromosomes in a total of 251 metaphase cells (2\%) in the patient's sample analyzed by FISH using PNA probes specific for human centromeres and telomeres [Livingston et al., 2018]. In the current study, 3 dicentric chromosomes were detected in 500 cells, showing a decline in frequency $(0.6 \%)$ after a span of 4 years since our last sampling in 2015. Out of the 5 donors examined, the sample of donor 5 displayed 7 dicentric chromosomes in 2,116 cells. The reason for the elevation of dicentric chromosome frequency is not clear, as this donor does not have any record of medical or occupational exposure prior to this study. In the age-matched donor 4, only 3 dicentric chromosomes were observed in 3,425 cells $(0.0009$ / cell). The average baseline frequency of dicentric chromosomes detected in the 5 healthy donors was $0.001 /$ cell relative to $0.006 /$ cell in the radioiodine patient (Table 1 ).

In contrast to the decline of dicentric chromosomes, the frequency of stable chromosome translocations detected by mFISH in this study ( 66 translocations in 669 cells in 2019 ; $9.86 \%)$ remained essentially the same as reported earlier (57 translocations in 600 cells; $9.50 \%$ in 2015) [Livingston et al., 2018] suggestive of long-time persistence of chromosome translocations. Using a standard in vitro $\mathrm{mFISH}$ calibration curve generated from the frequency of color junctions detected in $\gamma$-ray-treated lymphocytes, an absorbed whole-body dose of $0.51 \mathrm{~Gy}$ to the blood was estimated (lower confidence limit at 95\% CI 0.46 Gy; upper confidence limit at $95 \%$ CI 0.57 Gy) for the patient. As compared to the previous study where nonreciprocal and reciprocal translocations were detected at almost equal frequencies (45.62 and 54.38\%), the reciprocal translocation frequency $(80.30 \%)$ predominated in the current study indicating an increase of cells with balanced translocations probably owing to a selection bias. In addition to these simple translocations, 2 complex exchanges involving more than 2 chromosomes were de- 


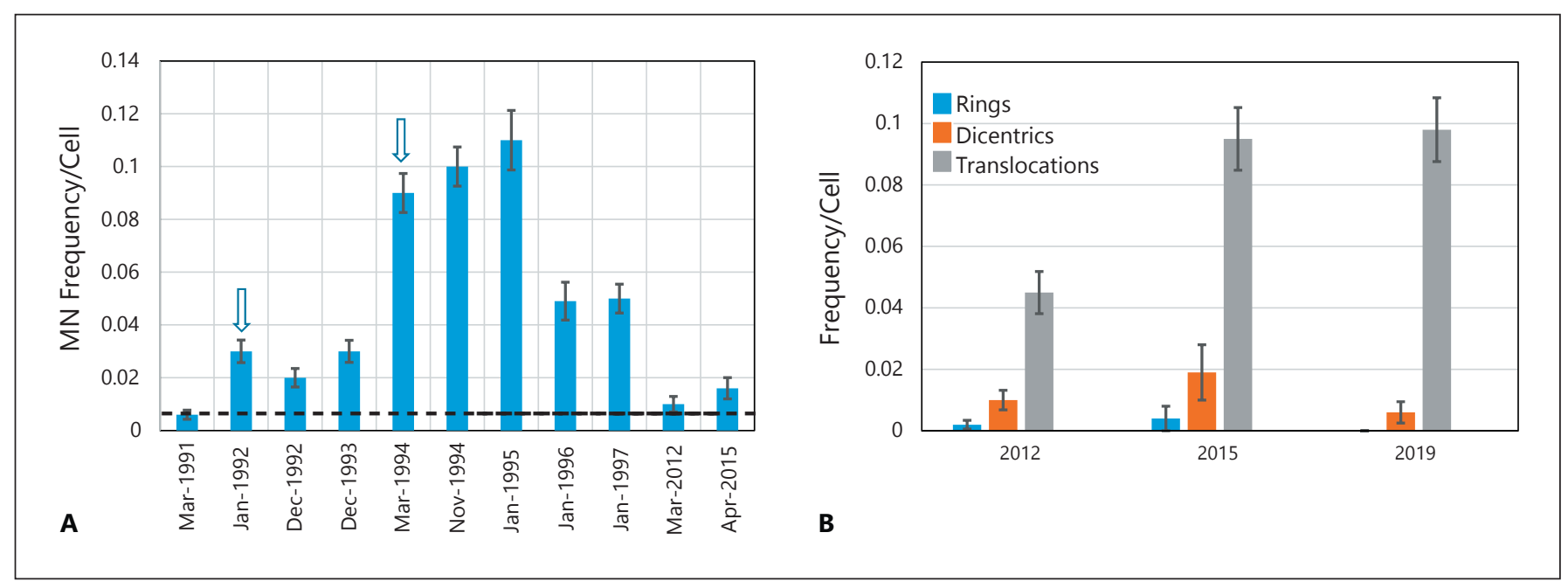

Fig. 1. Frequency of stable and unstable chromosome aberrations detected in the radioiodine patient. A Micronuclei (MN) frequency detected in cytokinesis-blocked binucleate cells before and after receiving the first (January 1992) and second (March 1994) round of radioiodine treatment (arrows) during the course of the longitudinal study. The dashed line indicates the baseline frequency of
$\mathrm{MN}$ detected in the patient prior to his diagnosis for papillary thyroid cancer. The increase in $\mathrm{MN}$ frequency, relative to the baseline detected in March 1991, was statistically significant $(p<0.05)$ for the post-treatment times. B Detection of unstable (dicentrics and rings) and stable (translocations) aberrations in the radioiodine patient from 2012 to 2019. tected for the first time in the patient, $\mathrm{t}(3 ; 6 ; 9)$ and $\mathrm{t}(8 ; 10$; 21) (0.29\%). Chromosomes 4, 9, 12, and 14 collectively contributed to $36.36 \%$ of the total translocation events. Of interest, 7 out of 677 cells analyzed by FISH using probes specific for chromosomes 14 and 15 showed the same translocation event involving chromosomes 14 and 15, $\mathrm{t}(14 \mathrm{p} ; 15 \mathrm{q})$, indicative of a clonal origin and expansion of $\mathrm{T}$ lymphocytes with this translocation (online suppl. Fig. 1; see www.karger.com/doi/10.1159/000504689). The existence of cells with the clonal translocation and complex exchanges, which were not detected previously, indicates the persistence and progression of RIT-induced chromosomal instability. Representative mFISH pictures of metaphase cells and their karyotypes with clonal and complex translocations are shown in Figure 2. Results on the baseline frequencies of stable and unstable chromosome aberrations detected by FISH and mFISH in the lymphocytes of healthy volunteers and the radioiodine patient are summarized in Tables 1 and 2. The frequency of translocations observed in the radioiodine patient was compared with the baseline frequency of translocations detected in the 5 healthy donors by mFISH to determine the magnitude of RIT-induced translocations. Results of $\mathrm{mFISH}$ on the involvement of specific chromosomes in simple, complex, and clonal translocations are summarized in Table 3 . Three of the 5 healthy volunteers did not show translocations while each of the other 2 donors showed 2 reciprocal translocations resulting in a baseline frequency of $0.017 /$ cell [ 2 in 115 cells; $t(17 ; 20)$ and $t(11$; $12)$ ] and $0.011 /$ cell [ 2 in 175 cells; $t(14 ; 18)$ and $t(5 ; 8)$ ], respectively. In the age-matched donor 4, 2 balanced translocations were observed in 175 cells, and the frequency of color junctions per cell was 0.02 . The frequency of color junctions observed in the radioiodine patient $(0.18 /$ cell $)$ was approximately 9-fold higher (Table 2 ). In corroboration with earlier studies [Salassidis et al., 1994, 1998; Tawn and Whitehouse, 2003; Lindholm and Edwards, 2004; Edwards et al., 2005; Duran et al., 2009; Khvostunov et al., 2017; Hartel et al., 2018], our results indicate a longterm persistence of translocations in humans with a past radiation exposure history.

Analysis of inter-arm (pericentric inversions) and intra-arm (paracentric inversions) exchanges was next performed using mBAND probes specific for chromosomes $1,2,4,5$, and 10. Results of the mBAND analysis are summarized in Table 4. The mBAND technique detected a total of 5 inversions [ 1 paracentric inversion in chromosome $1 \mathrm{q}, 2$ paracentric $(2 \mathrm{q}$ and $2 \mathrm{p})$ and 1 pericentric inversions in chromosome 2 , and 1 paracentric inversion in chromosome 4q] in 717 cells analyzed (0.007/cell). No inversions were observed for chromosomes 5 and 10 . Representative mBAND pictures with pericentric and paracentric inversions of chromosome 2 detected in the patient are shown in Figure 3. 


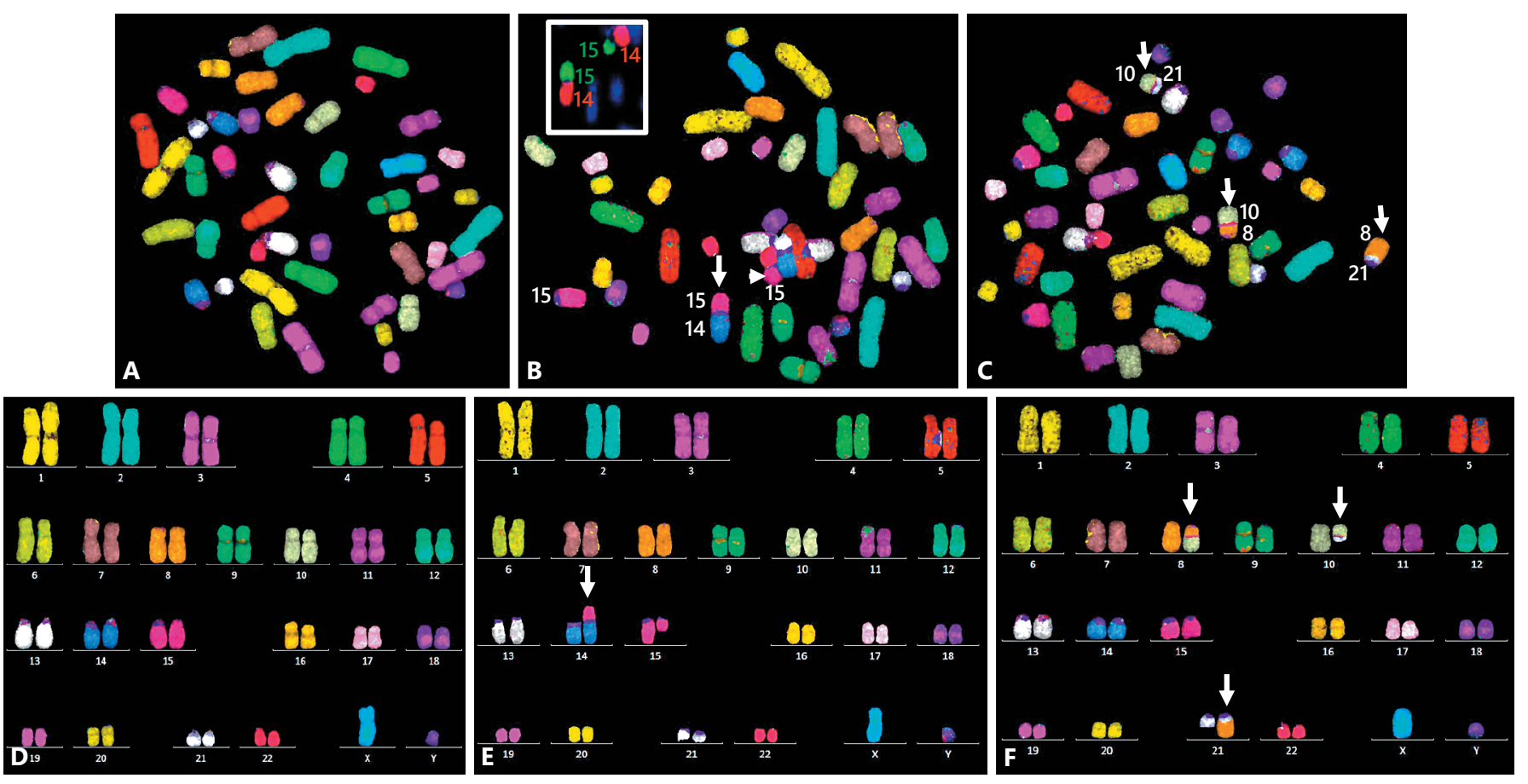

Fig. 2. Multicolor FISH detection of simple and complex chromosome exchanges in the peripheral blood lymphocytes of the radioiodine patient. A, D Normal metaphase cell (A) and karyotype (D). B, E Metaphase cell (B) and karyotype (E) with the clonal translocation involving chromosomes 14 and 15 (arrow). The arrowhead

\section{Frequency of X-Ray-Induced Chromosomal}

Aberrations in the Lymphocytes of the Radioiodine

Patient in vitro

Observation of elevated frequencies of chromosome translocations and inversions in the radioiodine patient prompted us to investigate the radio response of the patient's lymphocytes to ex vivo X-ray irradiation. Unstable aberrations (dicentric and ring chromosomes) and stable aberrations (simple and complex translocations) were analyzed by FISH and mFISH, respectively. Incidences of unstable chromosome aberrations observed in the patient were compared with the sample of a healthy donor (Table 5). The frequency of dicentric chromosomes detected by FISH using centromere- and telomere-specific PNA probes was found to be grossly similar in both samples for all the X-ray doses with the exception of 2 Gy that showed a much higher frequency of dicentrics and rings (0.73/ cell) in the radioiodine patient relative to the healthy individual (0.60/cell). Interestingly, the frequency of rings induced by $\mathrm{X}$-rays in the radioiodine patient sample was higher than in the healthy individual, and the reason for the differential induction of rings is not clear. indicates the incomplete chromosome 15 with centromere. Inset Sequential hybridization of the same metaphase cell with the whole chromosome paints specific for 14 and 15. C, F Metaphase cell (C) and karyotype (F) showing a complex chromosome exchange event involving chromosomes 8, 10, and 21 (arrows).
Frequencies of X-ray-induced genome-wide chromosome exchanges were next examined by mFISH through analysis of color junctions that included not only translocations (simple and complex) but also insertions and dicentrics. Table 6 summarizes the data obtained for simple and complex chromosome exchanges induced by different doses of X-rays in the radioiodine patient. In the unirradiated sample, 121 color junctions were observed in 669 cells $(0.18 /$ cell). In the 0.5 -Gy-irradiated sample, 136 color junctions were detected in 219 cells $(0.62 /$ cell $)$ that included 26 unbalanced translocations, 54 balanced translocations, and 25 dicentric chromosomes. In the 1-Gy-treated sample, 378 color junctions were found in 405 cells ( 53 unbalanced translocations, 158 balanced translocations, and 5 insertions) including complex chromosome exchanges involving more than 2 chromosomes at a frequency of $0.93 /$ cell. The number of color junctions dramatically increased after exposure to 2 Gy of X-rays with a frequency of 3.08/cell (657 color junctions in 213 cells analyzed: 142 unbalanced translocations, 221 balanced translocations, 12 insertions with 21 cells having com- 
Table 3. Cellular distribution of simple, clonal, and complex translocations detected in the radioiodine patient by mFISH

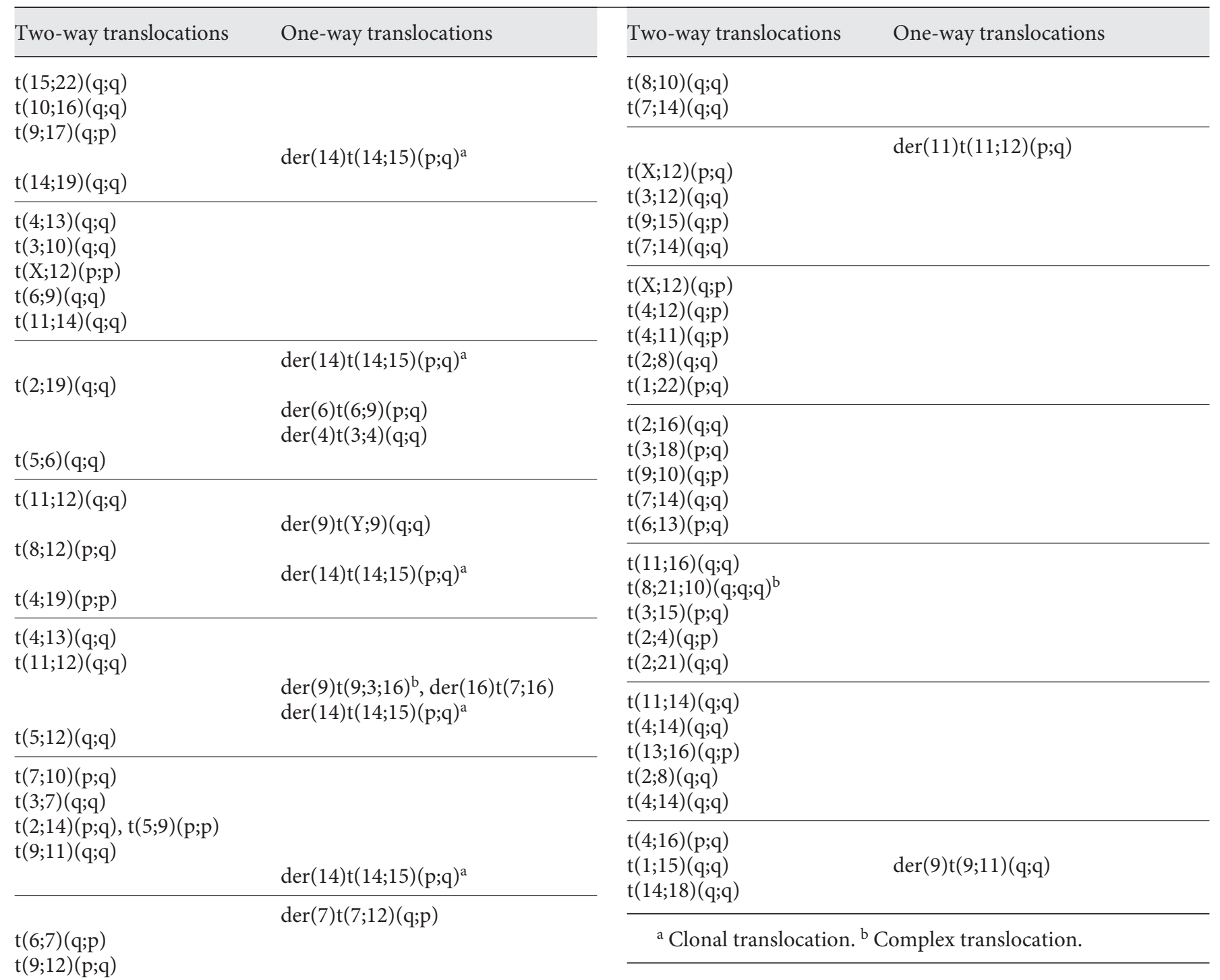

plex chromosome exchanges). Additionally, 132 dicentric and 1 tricentric chromosomes were detected by mFISH. Chromosomes 1, 2, and 3 were found to be involved in $45.73 \%$ of the total translocations induced by 2 Gy of X-rays. A representative picture of X-ray-induced chromosome exchanges in one of the cells with the clonal translocation $t(14 ; 15)$ is shown in Figure 4. In the 4-Gy-irradiated sample, the frequency of color junctions was found to be 7.18/cell (646 color junctions/90 cells) that included 86 dicentric and 2 tricentric chromosomes. Here, $70 \%$ of the cells displayed 2 or more chromosome exchange events, and 16.66\% showed chromosome insertion events.

Table 4. Baseline frequency of chromosome inversion events detected by mBAND

\begin{tabular}{|c|c|c|c|c|}
\hline \multirow[t]{2}{*}{ mBAND probe } & \multirow{2}{*}{$\begin{array}{l}\text { Cells } \\
\text { analyzed }\end{array}$} & \multicolumn{2}{|l|}{ Inversion } & \multirow{2}{*}{$\begin{array}{l}\text { Frequency } \\
\text { cell }\end{array}$} \\
\hline & & paracentric & pericentric & \\
\hline Chromosome 1 & 117 & 1 & 0 & 0.008 \\
\hline Chromosome 2 & 150 & 2 & 1 & 0.02 \\
\hline Chromosome 4 & 150 & 1 & 0 & 0.007 \\
\hline Chromosome 5 & 150 & 0 & 0 & 0 \\
\hline Chromosome 10 & 150 & 0 & 0 & 0 \\
\hline
\end{tabular}


Table 5. FISH analysis of X-ray-induced unstable aberrations in a normal healthy donor and the radioiodine therapy patient

\begin{tabular}{|c|c|c|c|c|c|c|c|}
\hline Sample & Age & Gender & Dose, Gy & Cells scored & Dicentrics & Rings & Aberration frequency/cell \\
\hline \multirow[t]{5}{*}{ Donor 6} & 40 & Male & 0 & 500 & 4 & 0 & 0.008 \\
\hline & & & 0.5 & 500 & 48 & 0 & 0.096 \\
\hline & & & 1 & 100 & 25 & 0 & 0.25 \\
\hline & & & 2 & 100 & 59 & 1 & 0.60 \\
\hline & & & 4 & 100 & 225 & 8 & 2.33 \\
\hline \multirow[t]{5}{*}{ Patient } & 61 & Male & 0 & 500 & 3 & 0 & 0.006 \\
\hline & & & 0.5 & 500 & 46 & 6 & 0.104 \\
\hline & & & 1 & 474 & 109 & 8 & 0.25 \\
\hline & & & 2 & 500 & 351 & 14 & 0.73 \\
\hline & & & 4 & 271 & 505 & 34 & 1.99 \\
\hline
\end{tabular}

${ }^{a}$ Includes both dicentrics and rings.

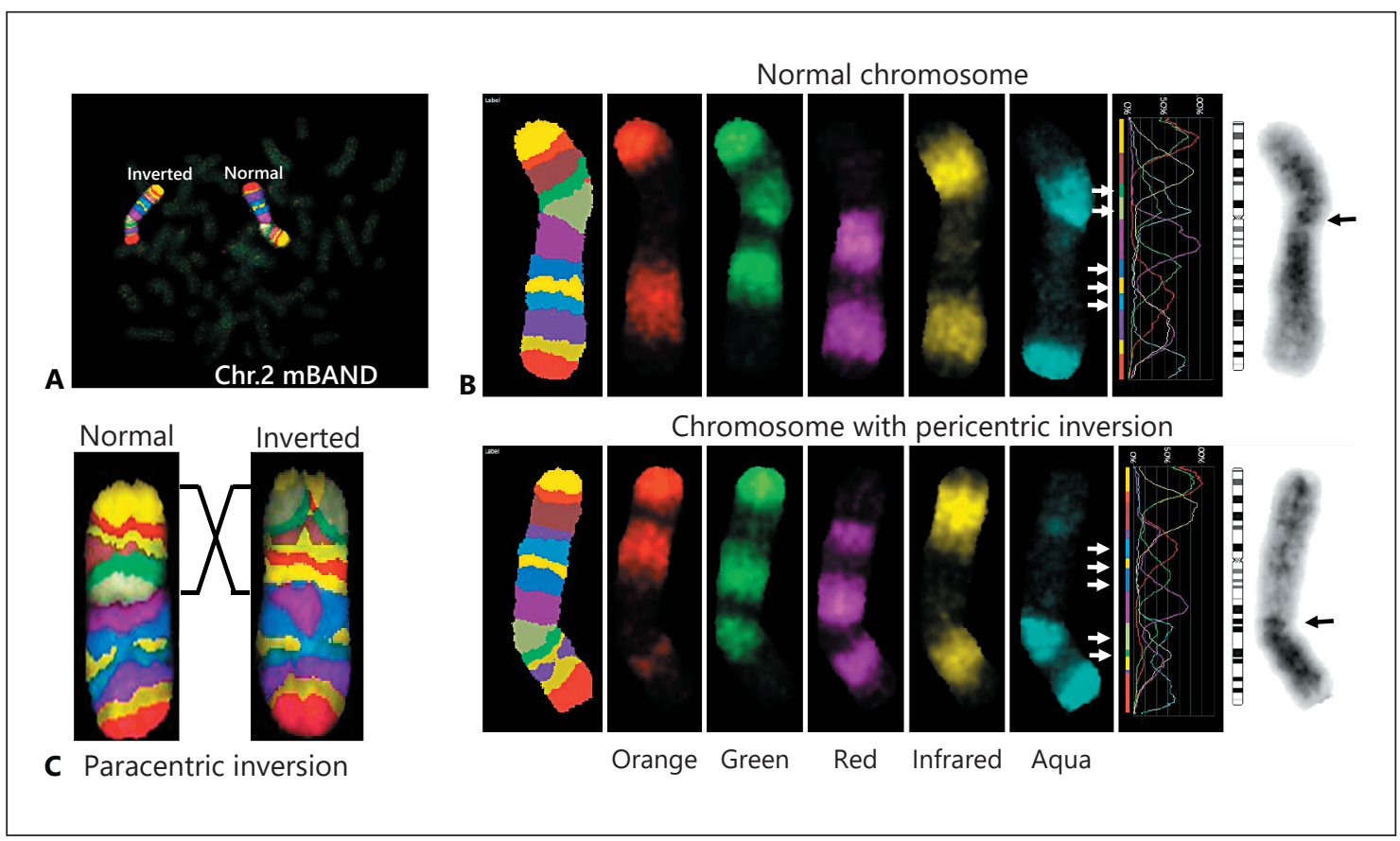

Fig. 3. Multicolor BAND analysis of chromosome inversions in the peripheral blood lymphocytes of the radioiodine patient. A Chromosome 2-specific mBAND hybridization patterns of normal and inverted chromosomes. B Distribution pattern of colored chromosome segments detected by 5 different fluorochromes in normal and inverted (pericentric inversion between chromosome arms involving the centromere; inter-arm exchange) chromosomes. Arrows indicate the inverted region of chromosome 2. C Representative picture of a paracentric inversion (intra-arm exchange) in chromosome 2 . Solid black lines indicate the inverted region.

\section{Discussion}

In this study, persistence and progression of RIT-induced chromosomal instability was examined after a span of 25 years in a radioiodine patient. Although the translocation frequency detected by mFISH in this study $(0.098 /$ cell) was similar to our earlier study performed in 2015 (0.095/cell) [Livingston et al., 2018], the percentage of cells with balanced translocations had increased considerably from 54.38 to $80.30 \%$, and this increase may be due to preferential selection of stable cells over cells with unstable aberrations. Additionally, complex chromosome exchanges 
Table 6. Multicolor FISH analysis of X-ray-induced chromosomal aberrations

\begin{tabular}{llcccccc}
\hline Dose, Gy & Cells scored & Aberrant cells & Dicentrics & Exchanges $^{\mathrm{a}}$ & Insertions & Color junctions & Aberrations/cell, mean \pm SEM \\
\hline 0 & 669 & 63 & 0 & 66 & 0 & 121 & $0.18 \pm 0.01$ \\
0.5 & 219 & 63 & 25 & $80(2)$ & 0 & 136 & $0.62 \pm 0.06$ \\
1 & 405 & 151 & 44 & $211(9)$ & 5 & 378 & $0.93 \pm 0.06$ \\
2 & 213 & 177 & 132 & $363(21)$ & 12 & 657 & $3.08 \pm 0.24$ \\
4 & 90 & 89 & 120 & $234(25)$ & 17 & 646 & $7.18 \pm 0.80$ \\
\hline
\end{tabular}

a The number of cells with complex exchanges involving more than 2 chromosomes is given in parentheses.

${ }^{\mathrm{b}}$ Color junctions include acentric fragments.
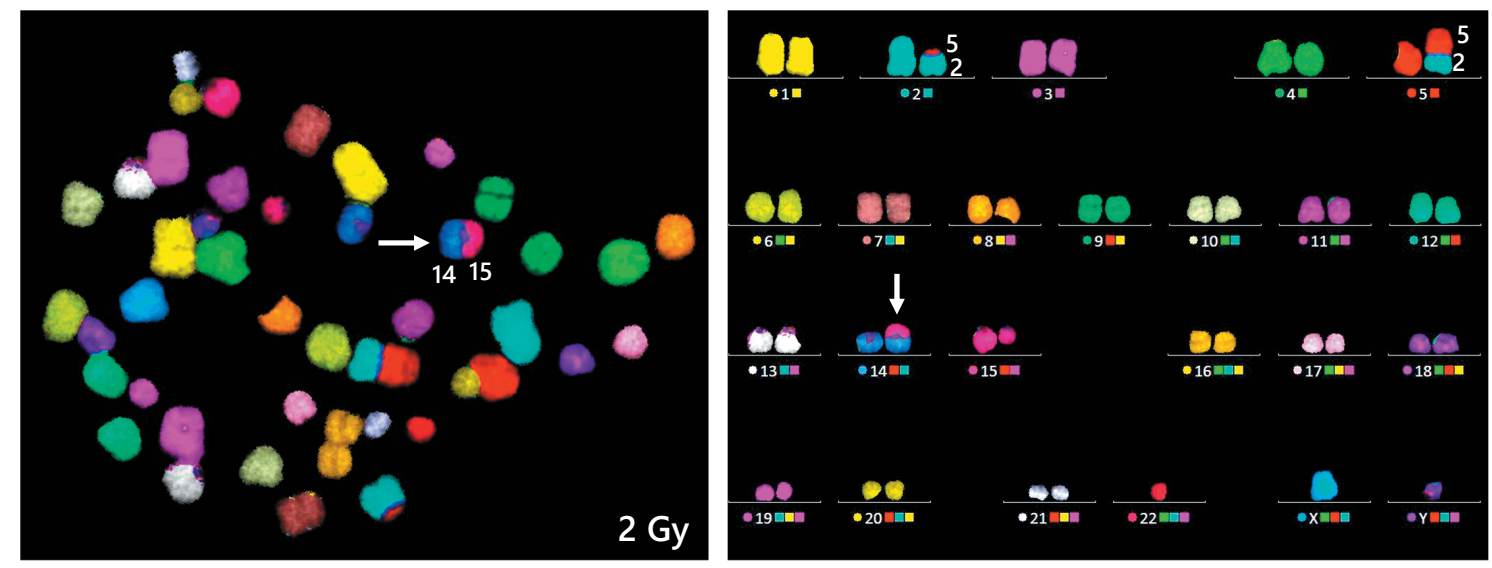

Fig. 4. Induction of chromosomal aberrations by $2 \mathrm{~Gy}$ of $\mathrm{X}$-rays in a metaphase cell with the clonal translocation $\mathrm{t}(14 ; 15)$ (arrow). Note the X-ray-induced translocation between chromosomes 2 and 5 in the mFISH karyotype.

were detected in 2 of 669 cells analyzed ( $0.003 /$ cell). Observation of an identical translocation event involving chromosomes 14 and 15 in 7 cells clearly indicated a clonal origin and expansion of this translocation in the peripheral T lymphocytes of this patient. For retrospective dosimetry purpose, it is generally accepted that the baseline translocation frequency as a function of age varies from 2 to 15 translocations (both balanced and unbalanced) per 1,000 GE cells for 20-80 years of age when detected by FISH using probes for large chromosome pairs that comprise $30-35 \%$ of the human genome [Edwards et al., 2005]. A previous study [Cigarrán et al., 2001] found an insignificant increase in the translocation frequency of occupational radiation workers at hospitals with estimated radiation doses up to $120 \mathrm{mSv}$ when compared with age-matched donors. Therefore, it can be inferred that the diagnostic exposure(s) received by the patient prior to RIT have not contributed significantly to the elevated translocation frequency detected in this study. In the present study, mFISH analysis was performed on the blood samples of 5 healthy donors whose age ranged from 40 to 61 years. Among the
5 donors, color junctions were found only in 2 donors ( 1 and 4): 2 males aged 42 and 61 years, respectively. Comparison with an age-matched male donor (donor 4, 61 years of age) indicates a 9 -fold increase in the frequency of chromosome translocations in the radioiodine patient. Despite an increase in the frequency of dicentric chromosomes $(0.003 /$ cell $)$, translocations were not detected in the sample of donor 5 (female aged 47 years). Likewise, donor 1 (42-year-old male) showed a translocation frequency of $0.05 /$ cell, but the frequency of dicentrics was less than the baseline (0.0005). The reason for the differential distribution of dicentrics and translocations is not clear.

Additionally, both inter- and intra-arm chromosome inversions were found at a frequency of $0.007 /$ cell. Observation of complex and clonal translocation events, which were not detected in our earlier studies [Livingston et al., 2016, 2018], clearly indicates the onset of RIT-induced chromosomal instability in this patient. Detection of complex and clonal translocations in this patient prompted us to verify whether these changes are due to a decline in DNA repair capacity. As DNA double-strand break 
repair-deficient rodent and human cells show potentiation of chromosomal aberrations after ionizing radiation exposure [Bryant, 2004; Natarajan et al., 2008; Pluth et al., 2008; George et al., 2009], we utilized ex vivo X-ray-induced chromosomal aberrations for assessing the radio response of the RIT-patient's sample. The frequency of ex vivo X-ray-induced chromosome aberrations observed in the radioiodine patient was grossly similar to that reported for normal healthy individuals [Livingston et al., 1993; Matsuoka et al., 1994; Natarajan et al., 1996; Roos and Schmid, 1998; Hoffmann et al., 1999, 2002; Knehr et al., 1999; Fomina et al., 2000; Darroudi et al., 2002; Ritter et al., 2002; Schröder and Heimers, 2002; Nasonova et al., 2006], indicating that the DNA repair capacity is not compromised by the past radioiodine treatment.

Earlier studies demonstrated RIT-induced cytogenetic damage in the blood lymphocytes of patients with thyroid cancer [Nofal and Beierwaltes, 1964; Cantolino et al., 1966; Sanders, 1967; Llloyd et al., 1976; Ardito et al., 1987; Lehmann et al., 1996; Wuttke et al., 1996; Lassmann et al., 2005; Popova et al., 2005; Iarmarcovai et al., 2008; Serna et al., 2008; Frigo et al., 2009; Joseph et al., 2009; da Silva et al., 2016; Livingston et al., 2016; Khvostunov et al., 2017]. Using the blood samples collected before and 3-4 days after ${ }^{131}$ I treatment (2-4 GBq), Khvostunov et al. [2017] analyzed both unstable (dicentrics and rings) and stable (translocations) chromosome aberrations in 24 patients with differentiated thyroid cancer who received ${ }^{131}$ I treatment either once or multiple times. The mean frequency of dicentrics and rings per 100 cells for single and multiple times treated groups was $1.82 \pm 0.15$ and $2.08 \pm 0.72$, respectively. The patient group with multiple treatments received ${ }^{131} \mathrm{I}$ in the range of $1.48-42.8 \mathrm{GBq}$ over the span of 1-14 years. The authors estimated that the mean wholebody absorbed radiation dose to blood ranged from 0.4 to $0.96 \mathrm{~Gy}$ for patients treated once and from 0.11 to $1.22 \mathrm{~Gy}$ for patients treated multiple times. The mean absorbed dose to blood estimated from the cytogenetic analysis of incomplete and complete translocations ranged from 0.83 to $1.92 \mathrm{~Gy}$. The mean translocation frequency/cell detected for 6 of the patients with multiple treatments was found to be $0.1 /$ cell for an average cumulative administration of $23.86 \mathrm{GBq}$ of ${ }^{131} \mathrm{I}$. A similar frequency of translocations $(0.09 /$ cell $)$ was found in the current study for the patient who received a cumulative administration of $16.28 \mathrm{GBq}$ of radioiodine. Medical Internal Radiation Dose (MIRD) procedures predicted a biodose of $0.23 \mathrm{mGy} / \mathrm{MBq}$ of ${ }^{131} \mathrm{I}$, while the biodose estimated by the micronucleus assay ranged from $0.089-0.197 \mathrm{mGy} / \mathrm{MBq}$, which was slightly less than the biodose estimated by chromosome aberration assay $(0.146 \mathrm{mGy} / \mathrm{MBq})$. Based on this biodose estimation, a whole-body absorbed dose in the range of 1.3-2.9 Gy to the blood was predicted for our patient. Using a $\gamma$-ray calibration curve generated by mFISH-based color junctions, an absorbed whole-body dose of $0.51 \mathrm{~Gy}$ to the blood was estimated (lower confidence limit at 95\% CI 0.46 Gy and upper confidence limit at 95\% CI $0.57 \mathrm{~Gy}$ ) after 25 years of RIT. As radioiodine emits both $\gamma$-rays and $\beta$-particles as decay products, dose estimation using our standard $\gamma$-ray calibration curve seems to be appropriate. It is generally accepted that the frequency of unstable chromosome aberrations such as dicentrics shows a time-dependent decline after radiation exposure, while stable aberrations like translocations persist for a longer time with or without a slight decline in frequency [Edwards et al., 2005]. Among the donors examined, the dicentric chromosome frequency was well over the baseline for donor 5 (0.003/cell), but the mFISH analysis performed on 100 cells did not detect any chromosome translocations. Likewise, the frequency of dicentric chromosomes found in the blood samples of donors 1 (0.0005) and 4 (0.0008) was below the baseline (0.001), but translocations were detected in both of them (0.05/cell for donor 1 and 0.02/cell for donor 4). Further studies on more donor samples are required to verify the differential distribution of dicentrics and translocations in the human population.

Persistence of RIT-induced chromosomal aberrations has been well-documented in the literature [M'Kacher et al., 1996, 1997, 1998; Livingston et al., 2016; Khvostunov et al., 2017]. M'Kacher et al. [1997] performed a sequential biodosimetry after a single ${ }^{131} \mathrm{I}$ treatment $(3.7 \mathrm{GBq})$ in a total of 50 patients diagnosed with differentiated thyroid cancer for varying post-exposure times ( 4 days, 3 months, 6 months, 1 year, and 2 years) by both conventional and FISH-based cytogenetic techniques. The mean dosimetric index over the period of 2 years did not differ much and was in the range of 0.52-0.42 Gy for dicentric chromosomes and $0.47-0.42$ for FISH-based translocations using a chromosome 4-specific probe. The half-life of radioiodine is estimated to be around 8 days, and therefore the absorbed radioiodine in the patient must have been eliminated several days after the first and second radioiodine treatments. Therefore, onset and persistence of RIT-induced chromosomal aberrations observed in this patient is most likely due to DNA damage induced in a subset of stem/progenitor cells that eventually give rise to Tlymphocytes with varying levels of stable and unstable aberrations. Alternately, persistence of chromosomal aberrations may also be due to long-lived naive $\mathrm{T}$ cells that can retain the initial damage inflicted by radioiodine treatment for long 
periods owing to their quiescent nature. Such cells with DNA damage can give rise to chromosomal aberrations when they are stimulated to proliferate in vitro.

To our knowledge, clonal chromosomal translocations induced by radioiodine treatment have not been reported earlier. The presence of identical translocation events involving chromosomes 14 and 15 in 7 of 677 cells analyzed suggests the clonal expansion of this translocation in circulating T lymphocytes. Interestingly, chromosomes 4, 9, 12 , and 14 constituted $36.36 \%$ of the total translocation events, and among them, chromosome 14 was found to be predominant. In an earlier study [Kusunoki et al., 1995], cells with clonal translocations involving $\mathrm{t}(4 ; 6)$ and $\mathrm{t}(5 ; 13)$ were observed in the lymphocytes of an atomic bomb survivor whose estimated whole-body absorbed dose was 1.95 Gy to red bone marrow. The authors suggested that the translocations most likely occurred in a stem/progenitor cell, which then would have contributed to the expansion of T- and B-cell lineages with clonal translocation(s). Future cytogenetic follow-up studies on our patient will verify whether circulating lymphocytes bearing the clonal translocation $t(14 ; 15)$ tend to increase retrospectively with time. However, the clonal translocation involving chromosomes $14 \mathrm{p}$ and $15 \mathrm{q}$ in the radioiodine patient has not yet been linked with any of the known human diseases.

In the present study, mBAND using chromosomespecific probes detected a total of 5 inversions in 717 cells. Thus, the inversion frequency recorded in the radioiodine patient is 11-fold higher than the baseline frequency reported by Herva [1981] who detected 10 recurrent chromosome 7 inversions in a total of 15,000 lymphocytes of 30 individuals with a frequency of $0.0006 /$ cell. This brief report did not specify either the age or gender of the individuals analyzed. So it is difficult to determine whether the spontaneous inversion frequency increases with age. Recently, McKenna et al. [2019] demonstrated a potential possibility of using chromosome translocations and inversions for retrospective biodosimetry. Applying the directional genomic hybridization technology, these authors investigated the blood samples of 12 US atomic veterans after 60 years of exposure from activities of nuclear testing procedures. Interestingly, the average of whole-GE frequency of inversions estimated from chromosomes 1, 2, and 3 was much higher than that for translocations ( $26.08 \pm 6.96$ and $6.58 \pm 4.62$, respectively). A similar trend was observed for the GE induction of translocations and inversions after $\gamma$-ray exposure of human lymphocytes in vitro. McKenna et al. [2019] suggested that a combination of translocations and inversions can significantly improve the precision of retro-

Retrospective Cytogenetic Study on a

Radioiodine Patient spective biodosimetry. Since inversion analysis was not performed in our earlier studies on the radioiodine patient, it is difficult to assess whether the inversion frequency has increased or decreased by the radioiodine treatment retrospectively. Collectively our study clearly demonstrates the long-term persistence and progression of RIT-induced chromosomal instability analyzed after several years of radioiodine exposure. We realize that the main limitation of this study is that only 1 patient's sample was utilized which makes it difficult to provide a consensus on RIT-induced chromosome instability and persistence. Further, interindividual variations exist for the kinetics of decline in stable and unstable chromosome aberrations in radiation-exposed human populations. Nevertheless, our results suggest that stable chromosome aberrations such as translocations and inversions can be useful as retrospective biodosimetry for monitoring chromosomal/genomic instability induced by RIT.

\section{Acknowledgements}

The authors are grateful to Dr. Carol J. Iddins, Director of REAC/TS for encouragement, help, and support.

\section{Statement of Ethics}

The study was performed in complete compliance with the guidelines approved by the Institutional Review Board protocol (ORAU000349). Blood collection was performed after obtaining the informed/written consent from the volunteers.

\section{Disclosure Statement}

The authors have no conflicts of interest to declare.

\section{Funding}

The financial support received from the US Department of Energy (DE-SC0014664) is gratefully acknowledged. REAC/TS is an organizational program of the Oak Ridge Institute for Science and Education and is operated by ORAU for the U.S.DOE. The content is solely the responsibility of the authors and does not reflect the official views or opinions of the U.S. DOE, ORISE, and ORAU.

\section{Author Contributions}

G.K.L., A.E.F., and A.S.B. performed conceptualization, project administration, supervision, data curation, and image analysis/ verification. T.L.R., T.L.S., and M.B.E. performed all the experiments, image acquisition, data curation and formal data analysis. A.S.B. wrote the manuscript. 


\section{References}

Ardito G, Lamberti L, Bigatti P, Cottino F: Comparison of chromosome aberration frequency before and after administration of ${ }^{131} \mathrm{I}$ in two groups of thyroid cancer patients. Tumori 73: 257-262 (1987).

Bryant PE: Repair and chromosomal damage. Radiother Oncol 72:251-256 (2004).

Cantolino SJ, Schmickel RD, Ball M, Cisar CF: Persistent chromosomal aberrations following radioiodine therapy for thyrotoxicosis. $\mathrm{N}$ Engl J Med 275:739-745 (1966).

Cigarrán S, Barquinero JF, Barrios L, Ribas M, Egozcue J, Caballin MR: Cytogenetic analyses by fluorescence in situ hybridization (FISH) in hospital workers occupationally exposed to low levels of ionizing radiation. Radiat Res 155:417-423 (2001).

Darroudi F, Bezrookove V, Fomina J, Mesker WE, Wiegant JC, et al: Insights into the sites of $\mathrm{X}$ ray and neutron induced chromosomal aberrations in human lymphocytes using COBRA-MFISH. Radiat Prot Dosimetry 99:189192 (2002).

da Silva MA, Valgôde FG, Gonzalez JA, Yoriyaz $\mathrm{H}$, Guimarães MI, et al: Cytogenetic and dosimetric effects of (131)I in patients with differentiated thyroid carcinoma: comparison between stimulation with rhTSH and thyroid hormone withdrawal treatments. Radiat Environ Biophys 55:317-328 (2016).

Duran A, Barquinero JF, Caballin MR, Ribas M, Barrios L: Persistence of radiation-induced chromosome aberrations in a long-term cell culture. Radiat Res 171:425-437 (2009).

Edwards AA, Lindholm C, Darroudi F, Stephan $\mathrm{G}$, Romm H, et al: Review of translocations detected by FISH for retrospective biological dosimetry applications. Radiat Prot Dosimetry 113:396-402 (2005).

Fomina J, Darroudi F, Boei JJ, Natarajan AT: Discrimination between complete and incomplete chromosome exchanges in X-irradiated human lymphocytes using FISH with pancentromeric and chromosome specific DNA probes in combination with telomeric PNA probe. Int J Radiat Biol 76:807-813 (2000).

Frigo A, Dardano A, Danese E, Davi MV, Moghetti $\mathrm{P}$, et al: Chromosome translocation frequency after radioiodine thyroid remnant ablation: a comparison between recombinant human thyrotropin stimulation and prolonged levothyroxine withdrawal. J Clin Endocrinol Metab 94:3472-3476 (2009).

George KA, Hada M, Jackson LJ, Elliott T, Kawata $\mathrm{T}$, et al: Dose response of gamma rays and iron nuclei for induction of chromosomal aberrations in normal and repair-deficient cell lines. Radiat Res 171:752-763 (2009).

Hartel C, Nasonova E, Fuss MC, Nikoghosyan AV, Debus J, Ritter S: Persistence of radiation-induced aberrations in patients after radiotherapy with C-ions and IMRT. Clin Transl Radiat Oncol 13:57-63 (2018).
Hengstler JG, Bockisch A, Fuchs J, Grimm W, Zapf AO, et al: Increase in DNA single-strand break rejoining by continuous exposure of human mononuclear blood cells to radioiodine ((131)I) in vitro. Int J Radiat Biol 72:607613 (1997).

Hershman JM, Okunyan A, Rivina Y, Cannon S, Hogen V: Prevention of DNA double-strand breaks induced by radioiodide- ${ }^{131}$ I in FRTL-5 thyroid cells. Endocrinology 152:1130-1135 (2011).

Herva R: $\operatorname{Inv}(7)$ as a recurrent aberration in human lymphocyte cultures. Hereditas 95:163164 (1981).

Hoffmann GR, Sayer AM, Joiner EE, McFee AF, Littlefield LG: Analysis by FISH of the spectrum of chromosome aberrations induced by $\mathrm{X}$-rays in G0 human lymphocytes and their fate through mitotic divisions in culture. Environ Mol Mutagen 33:94-110 (1999).

Hoffmann GR, Sayer AM, Littlefield LG: Higher frequency of chromosome aberrations in latearising first-division metaphases than in early-arising metaphases after exposure of human lymphocytes to X-rays in G0. Int J Radiat Biol 78:765-772 (2002).

IAEA: Cytogenetic Dosimetry: Applications in Preparedness for and Response to Radiation Emergencies (2011). https://www.iaea.org/ publications/8735/cytogenetic-dosimetryapplications-in-preparedness-for-and-response-to-radiation-emergencies

Iarmarcovai $G$, Ceppi $M$, Botta $A$, Orsiere $T$, Bonassi S: Micronuclei frequency in peripheral blood lymphocytes of cancer patients: a meta-analysis. Mutat Res 659:274-283 (2008).

Joseph LJ, Bhartiya US, Raut YS, Kand P, Hawaldar RW, Nair N: Micronuclei frequency in peripheral blood lymphocytes of thyroid cancer patients after radioiodine therapy and its relationship with metastasis. Mutat Res 675:3540 (2009).

Khvostunov IK, Saenko VA, Krylov V, Rodichev A, Yamashita S: Cytogenetic biodosimetry and dose-rate effect after radioiodine therapy for thyroid cancer. Radiat Environ Biophys 56:213-226 (2017).

Knehr S, Huber R, Braselmann H, Schraube H, Bauchinger M: Multicolour FISH painting for the analysis of chromosomal aberrations induced by $220 \mathrm{kV} \mathrm{X}$-rays and fission neutrons. Int J Radiat Biol 75:407-418 (1999).

Kusunoki Y, Kodama Y, Hirai Y, Kyoizumi S, Nakamura N, Akiyama M: Cytogenetic and immunologic identification of clonal expansion of stem cells into $\mathrm{T}$ and $\mathrm{B}$ lymphocytes in one Atomic-bomb survivor. Blood 86:2106-2112 (1995).

Lassmann M, Luster M, Hänscheid H, Reiners C: Blood dosimetry and dose-rate effects after radioiodine therapy of differentiated thyroid cancer. J Nucl Med 46:899 (2005).
Lassmann M, Hänscheid H, Gassen D, Biko J, Meineke $\mathrm{V}$, et al: In vivo formation of gamma-H2AX and 53BP1 DNA repair foci in blood cells after radioiodine therapy of differentiated thyroid cancer. J Nucl Med 51:13181325 (2010).

Lehmann L, Zitzelsberger H, Kellerer AM, Braselmann H, Kulka U, et al: Chromosome translocations in thyroid tissues from Belarussian children exposed to radioiodine from the Chernobyl accident, measured by FISHpainting. Int J Radiat Biol 70:513-516 (1996).

Lindholm C, Edwards A: Long-term persistence of translocations in stable lymphocytes from victims of a radiological accident. Int J Radiat Biol 80:559-566 (2004).

Livingston GK, Foster AE, Elson HR: Effect of in vivo exposure to iodine-131 on the frequency and persistence of micronuclei in human lymphocytes. J Toxicol Environ Health 40: 367-375 (1993).

Livingston GK, Khvostunov IK, Gregoire E, Barquinero JF, Shi L, Tashiro S: Cytogenetic effects of radioiodine therapy: a 20-year follow-up study. Radiat Environ Biophys 55: 203-213 (2016).

Livingston GK, Escalona M, Foster A, Balajee AS: Persistent in vivo cytogenetic effects of radioiodine therapy: a 21-year follow-up study using multicolor FISH. J Radiat Res 59:10-17 (2018)

Llloyd DC, Purrott RJ, Dolphin GW, Horton PW, Halnan KE, et al: A comparison of physical and cytogenetic estimates of radiation dose in patients treated with iodine-131 for thyroid carcinoma. Int J Radiat Biol Relat Stud Phys Chem Med 30:473-485 (1976).

Matsuoka A, Tucker JD, Hayashi M, Yamazaki N, Sofuni T: Chromosome painting analysis of $\mathrm{X}$-ray-induced aberrations in human lymphocytes in vitro. Mutagenesis 9:151-155 (1994)

McKenna MJ, Robinson E, Taylor L, Tompkins C, Cornforth MN, et al: Chromosome translocations, inversions and telomere length for retrospective biodosimetry on exposed U.S. atomic veterans. Radiat Res 191:311-322 (2019).

M'Kacher R, Legal JD, Schlumberger M, Voisin P, Aubert B, et al: Biological dosimetry in patients treated with iodine-131 for differentiated thyroid carcinoma. J Nucl Med 37:18601864 (1996).

M'Kacher R, Légal JD, Schlumberger M, Aubert B, Beron-Gaillard N, et al: Sequential biological dosimetry after a single treatment with iodine-131 for differentiated thyroid carcinoma. J Nucl Med 38:377-380 (1997).

M'Kacher R, Schlumberger M, Légal JD, Violot D, Beron-Gaillard N, et al: Biologic dosimetry in thyroid cancer patients after repeated treatments with iodine-131. J Nucl Med 39:825829 (1998). 
Nasonova EA, Shmakova NL, Komova OV, Mel'nikova LA, Fadeeva TA, et al: Cytogenetic effects of low-dose radiation with different LET in human peripheral blood lymphocytes. Radiat Environ Biophys 45:307-312 (2006).

Natarajan AT, Boei JJ, Vermeulen S, Balajee AS: Frequencies of $X$-ray induced pericentric inversions and centric rings in human blood lymphocytes detected by FISH using chromosome arm specific DNA libraries. Mutat Res 372:1-7 (1996).

Natarajan AT, Berni A, Marimuthu KM, Palitti F: The type and yield of ionising radiation induced chromosomal aberrations depend on the efficiency of different DSB repair pathways in mammalian cells. Mutat Res 642:8085 (2008).

Nofal MM, Beierwaltes WH: Persistent chromosomal aberrations following radioiodine therapy. J Nucl Med 5:840-850 (1964).

Pluth JM, Yamazaki V, Cooper BA, Rydberg BE Kirchgessner CU, Cooper PK: DNA doublestrand break and chromosomal rejoining defects with misrejoining in Nijmegen breakage syndrome cells. DNA Repair 7:108-118 (2008).
Popova L, Hadjidekova V, Hadjieva T, Agova S, Vasilev I: Cytokinesis-block micronucleus test in patients undergoing radioiodine therapy for differentiated thyroid carcinoma. Hell J Nucl Med 8:54-57 (2005).

Ritter S, Nasonova E, Furusawa Y, Ando K: Relationship between aberration yield and mitotic delay in human lymphocytes exposed to 200 $\mathrm{MeV} / \mathrm{u} \mathrm{Fe}$-ions or X-rays. J Radiat Res 43 Suppl:S175-S179 (2002).

Roos H, Schmid E: Analysis of chromosome aberrations in human peripheral lymphocytes induced by $5.4 \mathrm{keV}$ x-rays. Radiat Environ Biophys 36:251-254 (1998).

Ryan TL, Pantelias AG, Terzoudi GI, Pantelias GE, Balajee AS: Use of human lymphocyte G0 PCCs to detect intra- and inter-chromosomal aberrations for early radiation biodosimetry and retrospective assessment of radiation-induced effects. PLoS One 14:e0216081 (2019).

Salassidis K, Schmid E, Peter RU, Braselmann H, Bauchinger M: Dicentric and translocation analysis for retrospective dose estimation in humans exposed to ionising radiation during the Chernobyl nuclear power plant accident. Mutat Res 311:39-48 (1994).
Salassidis K, Braselmann H, Okladnikova ND, Pressl S, Stephan G, et al: Analysis of symmetrical translocations for retrospective biodosimetry in radiation workers of the Mayak nuclear-industrial complex (Southern Urals) using FISH-chromosome painting. Int $\mathrm{J} \mathrm{Ra-}$ diat Biol 74:431-439 (1998).

Sanders M: Chromosomal aberrations following radioiodine therapy. Can Med Assoc J 96: 1117-1118 (1967).

Schröder H, Heimers A: Chromosome aberrations induced in human lymphocytes by in vitro and in vivo X-rays. Mutat Res 517:167172 (2002).

Serna A, Alcaraz M, Navarro JL, Acevedo C, Vicente V, Canteras M: Biological dosimetry and Bayesian analysis of chromosomal damage in thyroid cancer patients. Radiat Prot Dosimetry 129:372-380 (2008).

Tawn EJ, Whitehouse CA: Persistence of translocation frequencies in blood lymphocytes following radiotherapy: implications for retrospective radiation biodosimetry. J Radiol Prot 23:423-430 (2003).

Wuttke K, Streffer C, Muller WU, Reiners C, Biko J, Demidchik E: Micronuclei in lymphocytes of children from the vicinity of Chernobyl before and after ${ }^{131}$ I therapy for thyroid cancer. Int J Radiat Biol 69:259-268 (1996). 